\title{
EDITORIAL
}

\section{Nuevo esquema de vacunación en México}

E n la última década, México ha alcanzado importantes avances en relación con el bienestar de la niñez. Ello se refleja en los indicadores internacionales diseñados para evaluar el nivel de salud de esa población, como es el de mortalidad en menores de cinco años. Dichos indicadores, permiten, además, dar seguimiento al impacto de acciones de prevención y control de enfermedades destinadas a disminuir la morbilidad y la mortalidad en la población menor de cinco años; entre ellas, destaca la vacunación universal.

En la historia reciente de la vacunación, podemos identificar pasos decisivos como el inicio del Programa Nacional de Inmunizaciones en 1973, año en el que se estableció la aplicación de las cuatro vacunas esenciales (antipolio, DPT, BCG y antisarampión), además del toxoide tetánico.

En 1990-1991 se realizó la Encuesta Nacional de Cobertura de Vacunación (ENCOVA), que demostró rezago en las coberturas. Ante estos resultados, se consideró necesario: establecer un órgano administrativo que definiera un solo esquema básico de vacunación para todo el país; realizar la gestión administrativa de todos los aspectos de planeación y operativos; incrementar la participación de todas la instituciones que conforman el sector salud, y llevar a cabo el seguimiento de las coberturas de tal manera que también se favoreciera la investigación en este campo.

En 1991, por decreto presidencial, se creó el Programa de Vacunación Universal y se fundó el Consejo Nacional de Vacunación (CONAVA), en el que hasta la fecha participan representantes de todas las instituciones del sector salud.

Entre las acciones de salud que más han beneficiado a los niños de México, destacan las efectuadas por el Programa de Vacunación Universal a cargo del CONAVA. Los avances logrados por este organismo en la cobertura de vacunación, muestran el esfuerzo que todas las instituciones del sector salud han rea- lizado en este ámbito: dicho esfuerzo ha permitido no sólo alcanzar los objetivos y las metas programadas sino incluso superarlas.

Las elevadas coberturas de vacunación y su incremento sostenido en varios países del mundo han contribuido a la erradicación de la poliomielitis en el continente americano. En México, en particular, el último caso se presentó durante 1990. Asimismo, desde 1991 no se han notificado casos de difteria, por lo que esta enfermedad se encuentra eliminada del territorio nacional.

En relación con el sarampión, desde julio de 1996 no se han presentado casos. Las coberturas de vacunación alcanzadas y la tendencia descendente de la morbilidad nos indican que podemos aspirar a la eliminación de esta enfermedad. Sin embargo, mientras esto no se logre en todo el mundo, existe el riesgo de que aparezcan nuevas epidemias aun con programas exitosos, debido a los intensos movimientos migratorios entre países y porque no es posible vacunar al 100\% de los niños; además, las fallas primarias y secundarias de la vacuna favorecen la formación de "bolsas de susceptibles", particularmente en poblaciones marginadas.

Al cierre de la semana epidemiológica número 52 de 1998, se presentaron 25 casos de tétanos neonatal, 166 casos de tos ferina en todas las edades y 23 de TB meníngea en menores de cinco años, las cifras más bajas de estos padecimientos en toda la historia de la salud pública de México.

En 1998, 25 años después del inicio del Programa Nacional de Inmunizaciones, se modificó el esquema básico de vacunación. Se sustituyó la vacuna antisarampión por la triple viral (SRP), que protege del sarampión, la rubéola y la parotiditis, para aplicarla a todos los niños y niñas que nacieron a partir del 1 de enero de ese año; la primera dosis se administra al año de edad, y a los niños de 6 a 7 años se les da una dosis 
como refuerzo. Asimismo, se inició la vacunación con Td entre escolares de sexto año y mujeres de 12 a 45 años de edad para protegerlos del tétanos y la difteria y como una estrategia para prevenir el tétanos neonatal.

Ahora, en 1999, se ha modificado nuevamente el esquema nacional de vacunación. La vacunación primaria con DPT a los dos, cuatro y seis meses de edad será sustituida por la vacuna pentavalente $(\mathrm{DPT}+\mathrm{HB}+$ Hib), que, además de inmunizar contra difteria, tos ferina y tétanos, ofrece protección contra Hepatitis $\mathrm{B}$ e infecciones graves por Haemophilus influenzae tipo $b$, como la meningitis, la neumonía y la septicemia. La vacuna DTP se conserva para ser administrada como refuerzo a los 2 y 4 años de edad.

Con la inclusión de cinco nuevos antígenos en el esquema básico de vacunación en los últimos dos años, México se coloca a la vanguardia en América Latina, en relación con la vacunación universal. Sostener el éxito de este programa y mantener las altas coberturas exigen un esfuerzo constante y la garantía de contar con recursos suficientes.

Dr. José Ignacio Santos Preciado* 